\title{
Gastrointestinal Disorders and Psychology
}

\author{
Mariela González Tovar* \\ Department of Psychology, Pontifical Catholic University of Chile, Chile
}

ISSN: 2637-7632

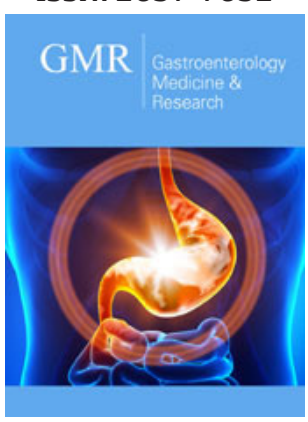

*Corresponding author: Mariela González Tovar, Department of Psychology, Pontifical Catholic University of Chile, Chile

Submission: 侮 June 12, 2020

Published: 㘹December 10, 2021

Volume 6 - Issue 3

How to cite this article: Mariela González Tovar. Gastrointestinal Disorders and Psychology. Gastro Med Res. 6(3). GMR. 000637. 2021.

DOI: 10.31031/GMR.2021.06.000637

Copyright@ Mariela González Tovar, This article is distributed under the terms of the Creative Commons Attribution 4.0 International License, which permits unrestricted use and redistribution provided that the original author and source are credited.

\section{Commentary}

Both depressive-anxiety symptoms and psychosocial stressors are elements involved in gastrointestinal disorders [1]. What is debatable is to clarify what is the role of these factors, either as consequence or as cause in the appearance, or in the recurrence of these diseases. It can be considered that in some cases there are symptoms where there is no structural injury, but they are of emotional origin; and others in which the psychic manifestations are only a repercussion of a primary gastrointestinal disease [1]. In the first case, it is obvious that the emotional component is essential in the onset, maintenance, and relapses of the disorder, and when there is organic injury, a disease that can occur autonomously is established. In the case of primary diseases, where a psychic etiology has not been demonstrated, it cannot be ignored that psychic factors can influence vulnerability to contracting diseases, since the organism varies its balance in the face of stress [2]. Current knowledge has not yet clarified the relationship between psychic factors and their organic impact. Over the past 30 years, human research has proposed a clinical relationship between stressful life events and higher rates of morbidity and mortality [2]. In the field of Gastroenterology, these studies are even more confusing, because they vary with respect to whether the variable under study is the beginning of the disease, the appearance of symptoms or the clinical presentation [3]. While, in the field of Psychology, one is usually more interested in the way in which environmental factors and behavior modify a patient's illness. Once an illness is established, cultural and family norms, as well as the psychological state and existential circumstances causing stress must be taken into account, since they tend to modify the behavior of the disease and perhaps even the disease itself. This is how social support and coping strategies can cushion these effects [4-6].

In usual gastroenterological practice, various psychiatric diagnoses are often observed, which are related to gastrointestinal disease [7]. Among these most frequent diagnoses are Anxiety: which consists of an unpleasant emotion that is accompanied by a feeling of threat or imminent danger of unknown or irrational origin, which may or may not be associated with a specific stimulus [8]. On the other hand, between episodes of stress at the origin and manifestation of symptoms of some gastrointestinal disease, relatively recent events can be distinguished, which mark the beginning of the symptoms or affect their severity, or early stress experiences in the life of the subject, which may manifest a predisposition to the development of this type of disorder. But the relationship with stress is not only here, since the disease is seen as a stressful event in the life of the person who suffers from it, highlighted by the alteration that the individual has in their quality of life [8]. 
Thus, it is seen that the nature of a psychopathological state in the context of a gastrointestinal disease must be clarified exclusively by clinical criteria [9]. The doctor's dialogue with the patient is the most important element of success in the diagnosis and treatment of discomfort that overwhelms the patient. That is why it is important to determine the respective influence of the biological, psychological and social dimension of the patient's disease, since it is unnecessary to subject the patient to superfluous studies and diagnoses, instead of exploring the psychological determinants possibly involved in the discomfort [10]. It is relevant to take advantage of the role of the psychologist in the gastroenterologist's care team, and what the new area of psychogastroenterology can contribute to the palliative care of the symptoms of gastrointestinal diseases, but also by guaranteeing a comprehensive approach, in defense of a biopsychosocial care [11]. Psychogastroenterology must be recognized by different health professionals as a scientific discipline, this will allow the development of research and care and intervention plans in the different medical teams, consolidating itself as an area that underlines the role of the psychologist in multidisciplinary teams.

\section{References}

1. Holmes T, Masuda M (1974) Life changes and illness susceptibility. In: Dohrenwend BS, Dohrenwend BP (Eds.), Stressful life events: Their nature and effects. John Wiley, New York, USA, pp. 45-72.
2. Shah E, Rezaie A, Riddle M, Pimentel M (2014) Psychological disorders in gastrointestinal disease: Epiphenomenon, cause or consequence? Annals of Gastroenterology 27(3): 224-230.

3. González M, De Ascencao M (2005) Irritable bowel syndrome. Psychological aspects. Journal of the Faculty of Medicine of the Central University of Venezuela 28(2): 139-145.

4. Oblitas L (2006) Psychology of health and quality of life. Thomson, Mexico.

5. Oblitas L (2006) Health psychology and chronic diseases. PSICOM, Bogotá.

6. Oblitas L (2005) Atlas of health psychology. PSICOM, Bogotá.

7. Dutta A, Chacko A (2016) Influence of environmental factors on the onset and course of inflammatory bowel disease. World J Gastroenterol 22(3): 1088-1100.

8. Keefer L (2018) Behavioural medicine and gastrointestinal disorders: The promise of positive psychology. Nat Rev Gastroenterol Hepatol 15(6): 378-386.

9. González M (2015) The importance of effective communication with a patient with a functional digestive disease. Rev Gen 69(4): 104-105.

10. González M (2015) Psychogastroenterology, a discipline with present and future. Rev Gen 69(2): 22.

11. Shoji T, Endo Y, Fukudo S (2018) Psycho-gastroenterology. In: Tominaga K, Kusunoki H. (Eds.), Functional Dyspepsia. Springer, Singapore.

For possible submissions Click below: 